\title{
A Comparative Analysis of Triband, Koch, Microstrip and Rectangular Carpet with Giuseppe Peano Fractal Antenna
}

\author{
Gaurav Pal Singh \\ M.Tech Scholar \\ Electronics and Communication \\ Engineering Deptt. \\ Amritsar College of \\ Engineering and Technology, Amritsar
}

\author{
Narinder Sharma \\ Associate Professor \\ Electronics and Communication \\ Engineering Deptt. \\ Amritsar College of Engineering \\ and Technology, Amritsar
}

\begin{abstract}
The different types of antennas such as tri-band, Koch, microstrip and rectangular carpet have been compared with proposed antenna (Giuseppe peano) in this manuscript. These antennas have been compared on the basis of performance parameters with the proposed antenna. The proposed antenna is designed on low cost FR4 glass epoxy substrate with dielectric constant 4.4 and dimensions $40 \times 38.90 \times 1.6 \mathrm{~mm}^{3}$. Proposed antenna designed by using resonant frequency of $4 \mathrm{GHz}$ and the frequency is shifted towards the lower side in the simulated and measured results. This shifted of frequency band shows the miniaturization of antenna and reduction in the size of antenna. HFSS V13 simulator is used to design and simulate the proposed antenna. The designed antenna can be used for different wireless applications.
\end{abstract}

Keywords

Koch, microstrip, FR4, HFSS

\section{INTRODUCTION}

Fractals are the different sets of the curves and the fractal shapes are obtained by transforming the structure of the element using specific rules [1]. The fractal geometry is used to achieve the multiband and wideband/broadband characteristics of antenna [2]. In today's world of mobile communication systems there is requirement of compact size antennas, which can be achieved by using miniaturization technique of the antennas [3]. This technique can be achieved by using two properties of fractal antenna such as selfsimilarity and space-filling [4]. Similarity property of the fractals means that some of the parts are of the same shape of the whole structure but at different scale [5] [6]. To achieve the miniaturization the space-filling property is used. By using this property the resonant frequency of antenna shifted towards the lower side, without affecting the overall dimensions of antenna [7] [8]. The fractal antennas are used in different wireless applications due to its unique advantages such as compact size, low profile, multiband and wideband characteristics.

In this paper a comparison of different antenna has been discussed on the basis of performance parameters such as return loss and gain. The detailed designs of the existing antennas and design of proposed antenna are discussed in section 2. The results of proposed and existing antennas are discussed in section 3 .

\section{ANTENNA DESIGN}

The existing antennas like tri-band [1], Koch [2], microstrip [3] and rectangular carpet [5] are shown in Figure 1, Figure 2,
Figure 3 and Figure 4 respectively. Tri-band and rectangular carpet antennas are designed on FR4 glass epoxy substrate with relative permittivity of 4.4 and thickness $1.6 \mathrm{~mm}$. Whereas, Koch and microstrip antennas are designed on Rogers RT Duroid substrate with relative permittivity of 2.2 and thickness $3.2 \mathrm{~mm}$.

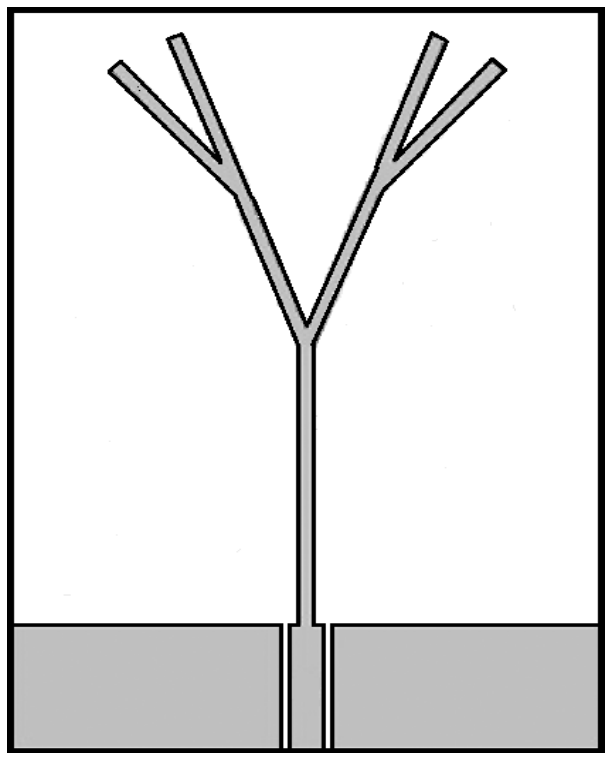

Figure 1: Tri-band antenna [1]

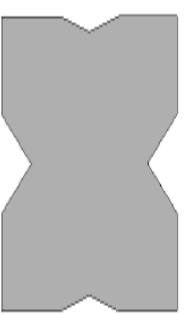

Ant 1

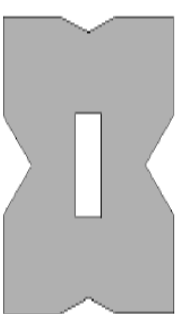

Ant2

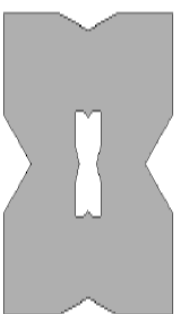

Ant3

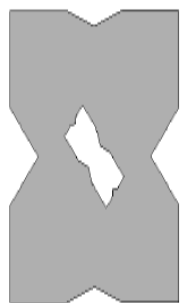

Ant4
Figure 2: Koch fractal antenna [2] 


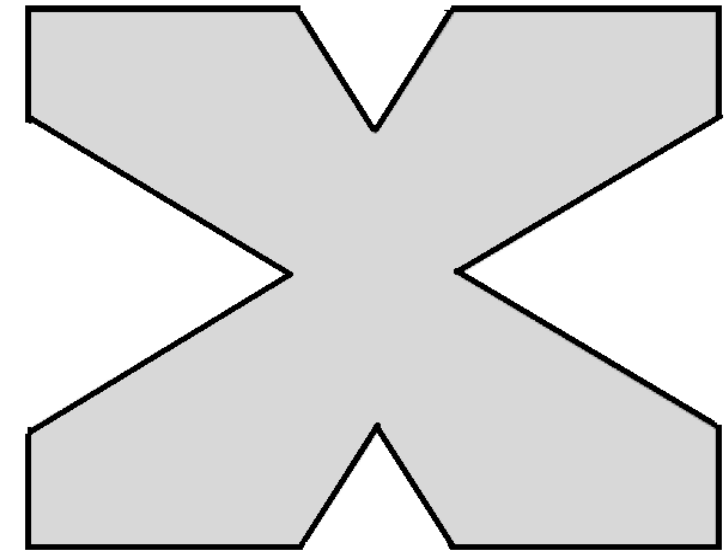

Figure 3: Microstrip fractal antenna [3]

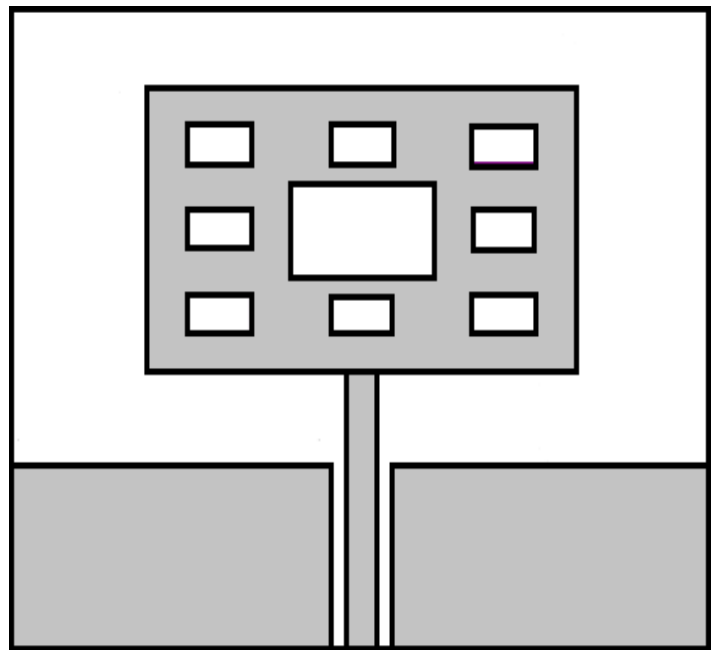

Figure 4: Rectangular carpet fractal antenna [5]

The proposed antenna is designed by using Giuseppe peano fractal technique. In this a rectangular patch is designed by using equation (1) to (5). Proposed antenna is designed on FR4 epoxy substrate having $\varepsilon_{r}=4.4$ and $\mathrm{h}=1.6 \mathrm{~mm}$ with resonant frequency $f_{r}=4 \mathrm{GHz}$. Length and width of patch of proposed antenna is calculated as $17 \mathrm{~mm}$ and $23 \mathrm{~mm}$ respectively.

$$
w=\frac{c}{2 f o \sqrt{\frac{\varepsilon_{r}+1}{2}}}
$$

$\varepsilon_{\text {reff }}=\frac{\varepsilon_{r}+1}{2}+\frac{\varepsilon_{r}-1}{2}\left[1+12 \frac{h}{w}\right]^{\frac{1}{2}}$

$L_{e f f f}=\frac{c}{2 f o \sqrt{\varepsilon_{r e f f}}}$

$\Delta L=0.412 h \frac{\left(\varepsilon_{\text {reff }}+0.3\right)\left(\frac{w}{h}+0.246\right)}{\left(\varepsilon_{\text {reff }}-0.258\right)\left(\frac{w}{h}+0.8\right)}$

$L=L_{e f f}+2 \Delta L$ $c=$ Velocity of light in free space.

$h=$ Substrate height.

$\mathcal{E}_{r}=$ Relative permittivity of the substrate.

$W=$ Width of rectangular patch.

$L=$ Length of rectangular patch.

$L_{\text {eff }}=$ Effective length.

$\varepsilon_{e f f}=$ Effective dielectric constant.

$f_{r=}$ Resonant frequency.

$\Delta L=$ Length extension.

The simulated and fabricated structure of proposed antenna is shown in Figure 5 and Figure 6 respectively. Width of substrate (Ws) and length of substrate (Ls) is $38.90 \mathrm{~mm}$ and $40 \mathrm{~mm}$ respectively. Microstrip line feed is used to provide the excitation with length $\left(\mathrm{L}_{\mathrm{F} 2}=13.96 \mathrm{~mm}\right)$ and width $\left(\mathrm{W}_{\mathrm{F} 2}=1.4 \mathrm{~mm}\right)$.

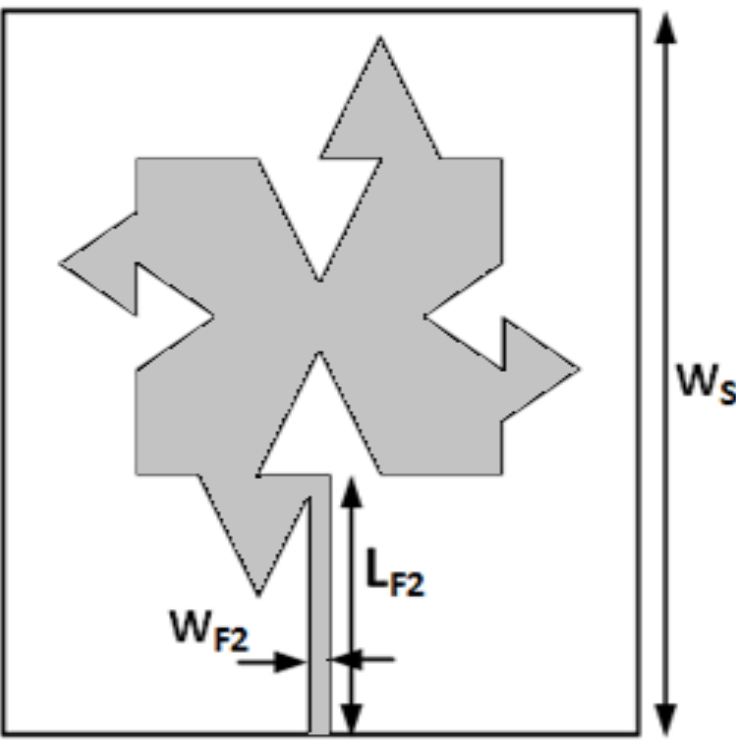

Figure 5: Simulated structure of proposed antenna

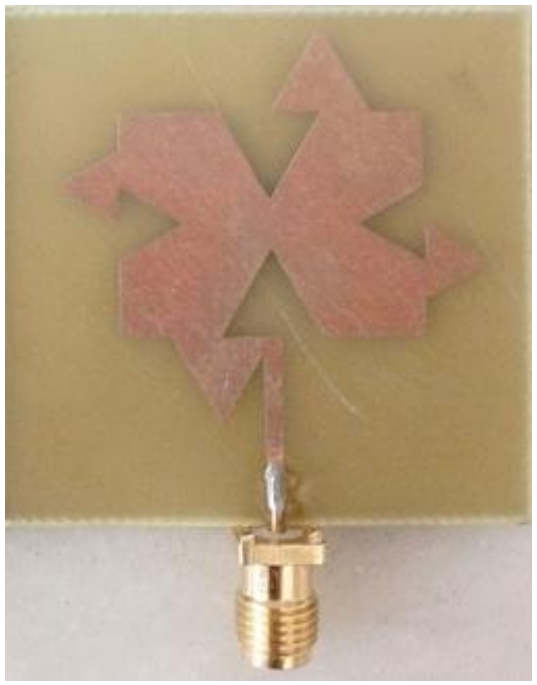

Figure 6: Fabricated structure of proposed antenna

Where, 


\section{RESULT AND DISCUSSIONS}

\subsection{Return loss}

$S_{11}$ characteristics of the existing antennas and proposed antenna have been discussed and compared in this section. The return loss graphs of existing antennas with respect to frequency are shown in Figure 7, Figure 8, Figure 9 and Figure 10 respectively. By analyzing all the return loss curves of existing antennas it has been found that the tri-band antenna works on three resonant frequency bands like $3.6 \mathrm{GHz}, 5.7 \mathrm{GHz}$ and $8.2 \mathrm{GHz}$. Similarly, Koch fractal antenna works on $2.45 \mathrm{GHz}, 3.4 \mathrm{GHz}$ and $5.8 \mathrm{GHz}$ frequency bands of operation. Microstrip antenna works on $2.4 \mathrm{GHz}$ and $3.3 \mathrm{GHz}$ frequency bands. Also, the rectangular carpet antenna works on two resonant frequencies like $3.6 \mathrm{GHz}$ and $7.1 \mathrm{GHz}$. The values of return loss for all the frequency bands of existing antennas are at the acceptable level.

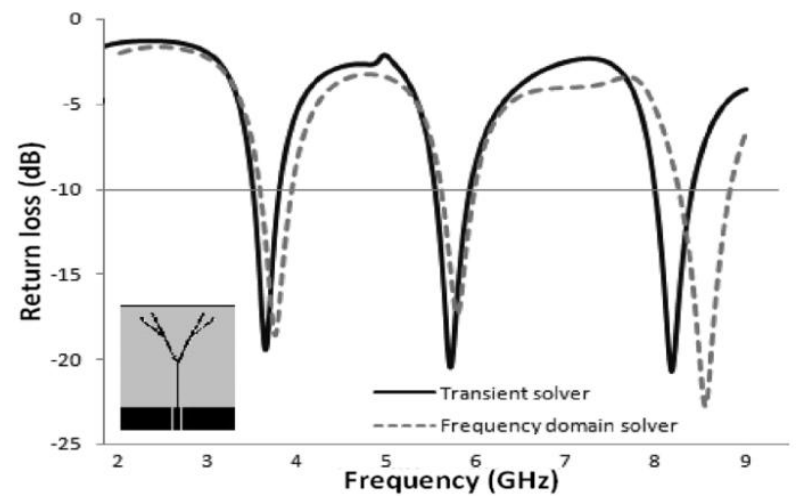

Figure 7: Return loss curve of tri-band antenna [1]

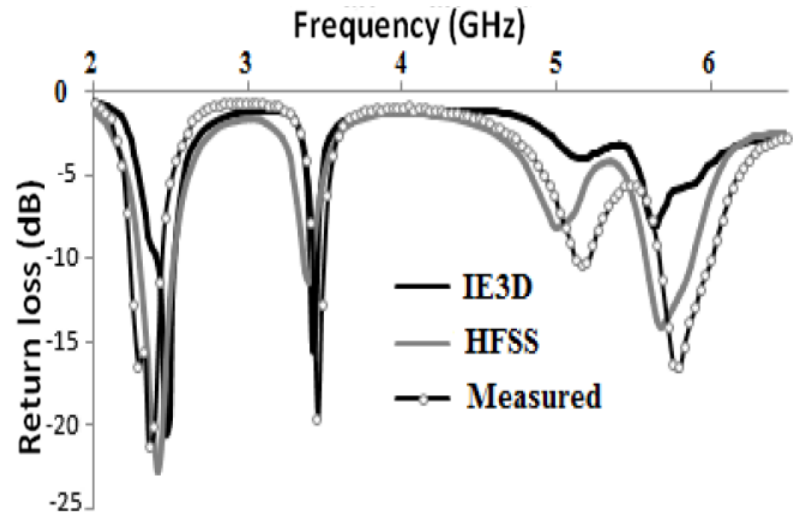

Figure 8: Return loss curve of Koch fractal antenna [2]

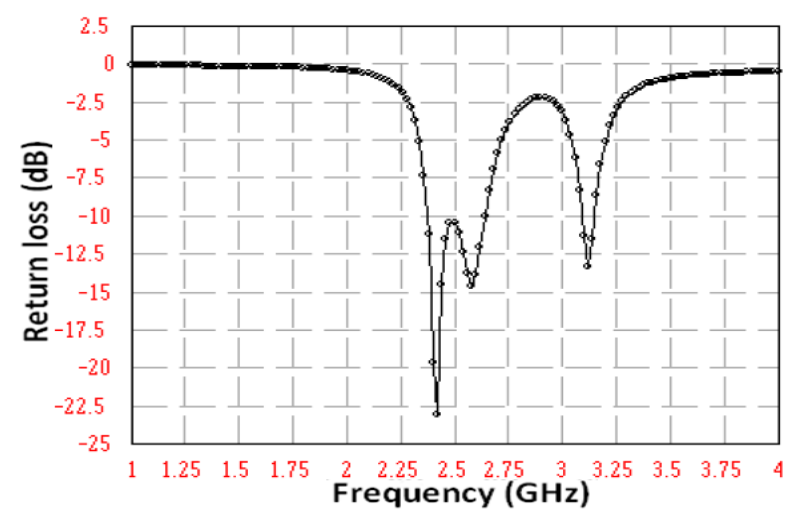

Figure 9: Return loss curve of microstrip fractal antenna [3]

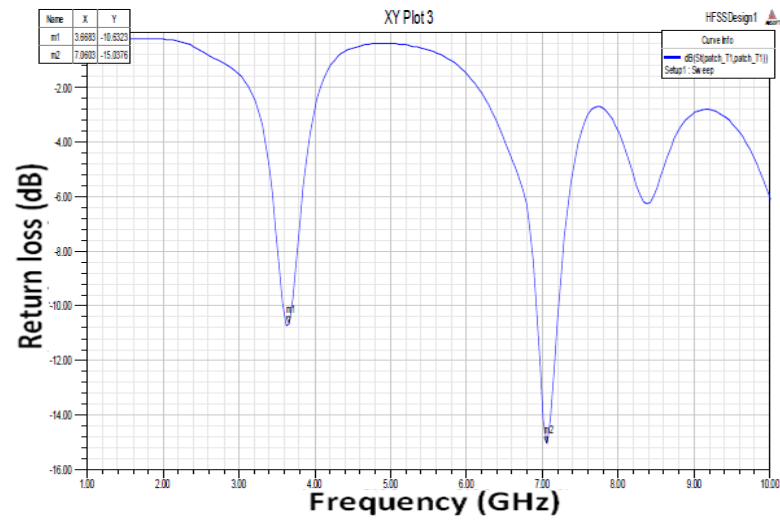

Figure 10: Return loss curve of rectangular carpet antenna [5]

The simulated return loss shows that the proposed antenna resonates at $2.10 \mathrm{GHz}, 2.85 \mathrm{GHz}, 5.18 \mathrm{GHz}$ and $9.11 \mathrm{GHz}$ with bandwidth of $90 \mathrm{MHz}, 90 \mathrm{MHz}, 110 \mathrm{MHz}$ and $800 \mathrm{MHz}$ respectively. In the same manner the measured return loss of proposed antenna resonates at $3.01 \mathrm{GHz}, 5.39 \mathrm{GHz}$ and $9.74 \mathrm{GHz}$ with bandwidth of $90 \mathrm{MHz}, 140 \mathrm{MHz}$ and $550 \mathrm{MHz}$ respectively. Initially, the proposed antenna is designed by taking the resonant frequency of $4 \mathrm{GHz}$. By observing the simulated and measured results of proposed antenna, it has been concluded that the resonant frequency has been reduced towards the lower side. The reduction of resonant frequency towards the lower side without changing the overall dimensions of proposed antenna means the miniaturization has been achieved. The simulated and measured return loss curve of proposed antenna is shown in Figure 11.

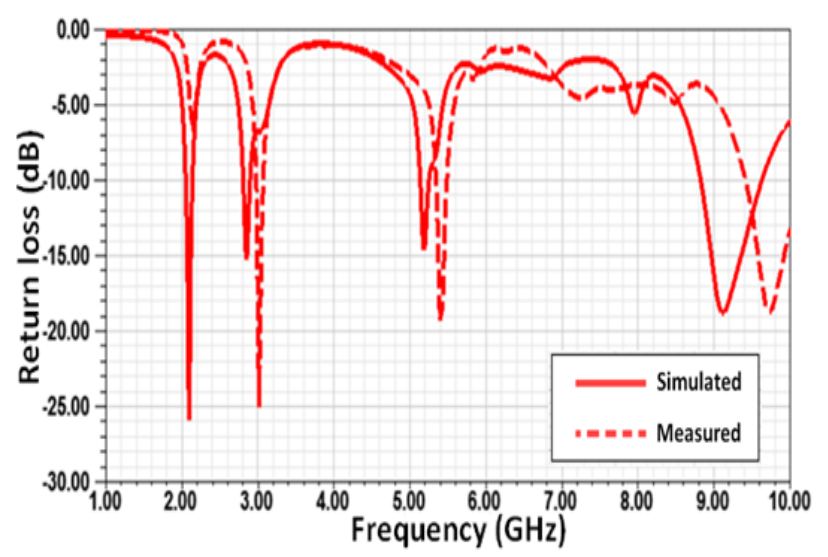

Figure 11: Return loss curve of proposed antenna

\subsection{Gain}

The tri-band [1] antenna shows the value of gain as $3.4 \mathrm{~dB}$, $2.7 \mathrm{~dB}$ and $2.6 \mathrm{~dB}$ at the respective frequency band. Koch fractal [2] antenna shows the value of gain as $6.8 \mathrm{~dB}, 4.9 \mathrm{~dB}$ and $2.8 \mathrm{~dB}$ at respective frequency band. Similarly, the microstrip fractal [3] and rectangular carpet [5] shows the overall gain of $4 \mathrm{~dB}$ and $3.8 \mathrm{~dB}$ respectively. To increase the gain and the resonant frequencies the proposed antenna is designed. Proposed antenna works on four different resonant frequency bands of operation with the value of gain $3.14 \mathrm{~dB}$, $4.54 \mathrm{~dB}, 2.57 \mathrm{~dB}$ and $8.02 \mathrm{~dB}$ respectively.

\section{CONCLUSIONS}

Comparisons of different existing antennas such as tri-band [1], Koch [2], microstrip fractal [3] and rectangular carpet [5] have been made with the proposed antenna (Giuseppe peano) 
in this paper. By observing the results of existing antennas and proposed antenna, it has been concluded that the maximum gain of existing antennas is $6.8 \mathrm{~dB}$. The proposed antenna shows the maximum value of gain as $8.02 \mathrm{~dB}$. In some of the existing antennas the gain is calculated only at the resonant frequency band, but in the proposed antenna the gain is calculated at all the frequency bands of operation. Proposed antenna also works on more number of frequency bands as compared to the existing antennas.

\section{REFERENCES}

[1] C. Vardadhan, J. K. Pakkathillam, M. Kanagasabai, R. Sivasamy, R. Natarajan and S. K. Palaniswamy, "Triband antenna structures for RFID systems deploying fractal geometry," IEEE Antenna and Wireless Propagation Letter, Vol. 12, pp. 437-440, 2013.

[2] V. V. Reddy and N. V. S. N. Sarma, "Triband circularly polarized Koch fractal boundary microstrip antenna," IEEE Antenna and Wireless Propagation Letter, Vol. 13, pp. 1057-1060, 2014.

[3] P. M. Jumle, P. Zade, R. Bhatkuikar, S. Tiwari, R. Ratulkar, Y. Kale, J. Dhore and S. Gohane, "Design of a fractal microstrip antenna for wireless applications," IEEE International Conference on Electrical, Electronics, Signals, Communication and Optimization (EESCO), 2015 .
[4] J. S. Sivia and S. S. Bhatia, "Design of fractal based microstrip rectangular patch antenna for multiband applications," IEEE International Advance Computing Conference (IACC), pp. 712-715, 2015.

[5] V. Dinesh and G. Karunakar, "Analysis of microstrip rectangular carpet shaped fractal antenna," SPACES, pp. 531-535, 2015.

[6] S. Yadav, P. Jain and R. Choudhary, "A novel approach of triangular circular fractal antenna," IEEE International Conference on Advances in Computing, Communications and Informatics (ICACCI), pp. 708711, 2014.

[7] A. Kaur and N. Sharma , "A quad band circular patch antenna with fractal elements for S-band and C-band applications," International Journal of Computer Applications, Vol. 144, No. 3, pp. 1-4, 2016.

[8] D. S. Sagne, R. S. Batra and P. L. Zade, "Design of modified geometry sierpinski carpet fractal antenna array for wireless communication," $3^{\text {rd }}$ IEEE International Advance Computing Conference (IACC), pp. 435-439, 2013. 